\title{
Síndrome de Budd Chiari agudo
}

\author{
Rafael Ramírez Montesinosa, Virginia Moreno Arias ${ }^{\mathrm{b}}$, \\ Tomás Sempere Dura ${ }^{c}$, Enric Pedrol Clotet $^{a}$
}

a Servicio de Medicina Interna, Hospital Sant Pau i Santa Tecla, Tarragona. España.

b Servicio de Medicina Familiar y Comunitaria. Hospital Sant Pau i Santa Tecla, Tarragona. España.

c Servicio de Radiología, Hospital Sant Pau i Santa Tecla, Tarragona. España.

Correspondencia: Virginia Moreno Arias, medicina Familiar y Comunitaria, Hospital Sant Pau i Santa Tecla, Rambla Vella no 14, 43003 - Tarragona, España. Telf.: 977259900 , fax: 977234942, e-mail: virgi_morearias@hotmail.com.

Recibido el 16 de marzo de 2011.

Aceptado para su publicación el 20 de abril de 2011

\section{RESUMEN}

El Sindrome de Budd Chiari se caracteriza por la obstrucción del retorno venoso de los venas hepáticas, la vena cava inferior o la aurícula derecha. El presente caso ilustra el índice de sospecha clínica necesario para el diagnóstico precoz del Síndrome de Budd Chiari cuando las pruebas complementarias iniciales (transaminasasas y ECO Abdominal) no son concluyentes. Palabras Clave. Síndrome de Budd-Chiari, Trombosis de la vena hepática derecha, Anticonceptivos Orales.

\section{ABSTRACT}

\section{Acute Budd Chiari Syndrome}

Budd Chiari Syndrome is characterised by the obstruction of venous return of the hepatic veins, the inferior vena cava and the right atrium. This case illustrates the index of clinical suspicion necessary for early diagnosis of Budd Chari Syndrome when initial complementary tests (transaminases and abdominal ultrasound) are not conclusive.

Key words. Budd Chiari Syndrome, Thrombosis of right liver vein, Contraceptives Oral.

\section{INTRODUCCIÓN}

El Síndrome de Budd Chiari se caracteriza por la obstrucción del retorno venoso de los venas hepáticas, la vena cava inferior o la aurícula derecha. Las formas de presentación aguda y fulminante requieren de un elevado índice de sospecha para su diagnóstico como se refleja en el caso que describimos.

\section{OBSERVACIONES CLÍNICAS}

Mujer de 25 años, fumadora y en tratamiento con anticonceptivos orales que refería astenia, náuseas y distensión abdominal progresiva en las últimas 3 semanas. A la exploración destacaba la semiología de moderada ascitis, con una hepatomegalia homogénea e indolora de 2 traveses de dedo, sin signos de irritación peritoneal o edemas.

En la analítica urgente se objetivó una plaquetopenia de $110.000 \mathrm{cel} / \mathrm{mm}^{3}$, tiempo de Quick de 1,25 y bioquímica del líquido ascítico con 190 leucocitos, glucosa y LDH normales y gradiente de albúmina superior a $1,1 \mathrm{grs} / \mathrm{dl}$. El resto de parámetros resultaron normales y la ECO-Doppler abdominal objetivó un hígado aumentado difusamente de tamaño con ascitis moderada y un flujo portal normal con calibre venoso de $1 \mathrm{~cm}$. Tanto la vena cava como las venas suprahepáticas media e izquierda eran permeables, sin visualizarse la vena suprahepática derecha.

Se inició heparina de bajo peso molecular (HBPM) a dosis descoagulantes y diuréticos de asa, suspendiéndose los anticonceptivos orales y con la sospecha de Sindrome de Budd-Chiari. El estudio de hepatopatía, incluyendo electroforesis de proteinas, hierro, ceruloplasmina, alfafetoproteina, TSH, FR, 
ANAs, Anti DNA, AMA, Anti RNP, Anti Ro, Anti LA, AMA, Anti LKM, Anti Musculo liso, RPR y serologías de virus hepatotropos (VHA, VHB, VHC), fue negativo. Los anticuerpos anticardiolipina (IgM 60 $\mathrm{u} / \mathrm{ml}$, IgG $22 \mathrm{U} / \mathrm{ml}$ ) y el antígeno carbohidratado $125(424.5 \mathrm{U} / \mathrm{mL}, 0-35)$ resultaron positivos.

A las 18 horas de su llegada a urgencias se realizó un Angio TAC abdominal en fases arterial, portal y venosa tardía, que confirmó la existencia de una hepatomegalia homogénea sin LOEs y una trombosis de la vena hepática derecha (figura 1). La paciente fue trasladada a un hospital de tercer nivel, donde se realizó una flebografía que confirmó una estenosis de la unión cava-suprahepática derecha, implantándose un STENT. Fue dada de alta bajo tratamiento con furosemida y acenocumarol, aunque no acudió a los controles posteriores.

\section{COMENTARIOS}

El presente caso ilustra el índice de sospecha clínica necesario para el diagnóstico precoz del Síndrome de Budd Chiari cuando las pruebas complementarias iniciales (transaminasasas y ECO Abdominal) no son concluyentes. Las formas agudas suelen presentarse con elevaciones de la ALT, en ocasiones de hasta 5 veces su valor normal ${ }^{1,2}$, mientras que la ECO-Doppler abdominal es considerada el método diagnóstico gold standard ${ }^{\beta}$, con una sensibilidad superior al $85 \%$. Igualmente

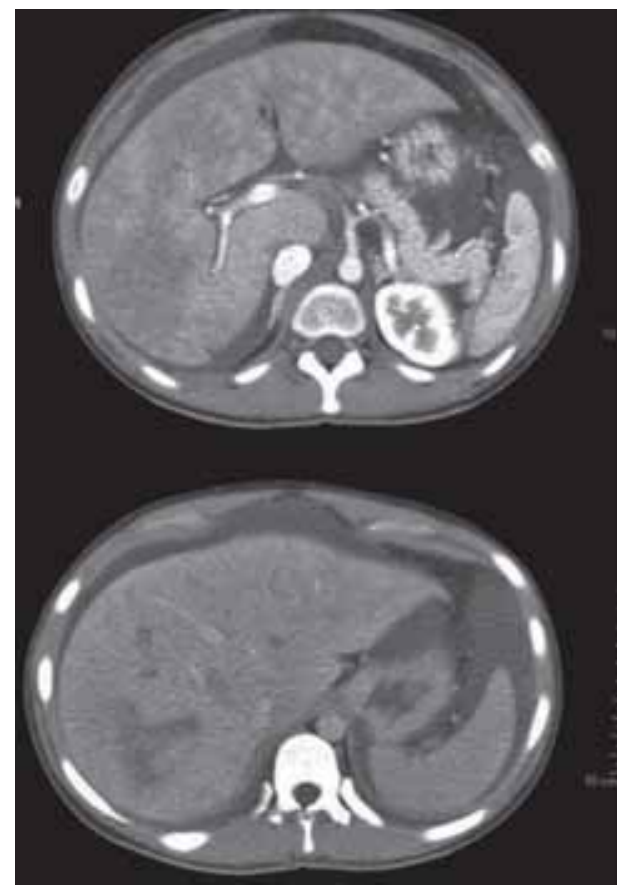

refleja cómo el tratamiento con anticonceptivos orales suele revelar un trastorno en la hemostasia subyacente ${ }^{4,5}$, en nuestro caso un probable síndorme antifosfolipídico que lamentablemente no pudo ser confirmado con la segunda determinación serológica al perderse el seguimiento.

Dado la importancia del tratamiento específico precoz, consideramos interesante recalcar la importancia de la sospecha clínica necesaria en casos con negatividad de las pruebas complementarias iniciales similares a nuestro caso.

\section{BIBLIOGRAFÍA}

1. Espinosa G, Font J, García-Pagan JC, Reverter JC, Gaig $C$, Cervantes F, et al. Budd-Chiari syndrome secondary to antiphospholipid syndrome: clinical and immunologic characteristics of 43 patients. Medicine (Baltimore). 2001; 80:345.

2. Rautou PE, Moucari R, Cazals-Hatem D, Escolano S, Denie C, Douarin L, et al. Levels and initial course of serum alanine aminotransferase can predict outcome of patients with Budd-Chiari syndrome. Clin Gastroenterol Hepatol. 2009; 7:1230.

3. Gupta S, Barter S, Phillips GWL, Gibson RN, Hodgson HJ. Comparison of ultrasonography, computed tomography and $99 m$ TC liver scan diagnosis of Budd-Chiari syndrome. Gut. 1987; 28:242.

4. Perarnau JM, Bacq Y. Hepatic vascular involvement related to pregnancy, oral contraceptives, and estrogen replacement therapy. Semin Liver Dis. 2008; 28:315.

5. Valdés Mas M, Martínez Pascual C, Egea Valenzuela J, Martínez Bonil MC, Vargas Acosta AM, Ortiz Sánchez ML, et al. Bilateral pulmonary thromboembolism and BuddChiari syndrome in a patient with Crohn's disease on oral contraceptives. Rev Esp Enferm Dig. 2009; 101(9):645-52.

Figura 1. TAC helicoidal en fases arterial y venosa tardía mostrando amplia alteración hipodensa en lóbulo hepático derecho, visualizándose buena contrastación de rama derecha de la vena porta y signos de trombosis de vena suprahepática derecha. Existe abundante líquido libre intraperitoneal. 